\title{
Politeness In Children's Language: Peer Group Influence and Pragmatic Competence
}

\author{
Lucy Khawardi \\ Universitas Negeri Medan \\ North Sumatera, Indonesia \\ Lucykhawardi88@gmail.com
}

\begin{abstract}
This study is concerned with a politeness in children's language when they play. The results of this empirical study of Langsa children's language in playing, focusing on their use of politeness phenomena. The data were obtained from students of kindergarten in Langsa. The children used as participants in this study were five boys and five girls. The children came from middle-class families and were aged between 5 and 8 years old. And the results from the present study, most of which has found that girls appear to be more polite than boys when they play. This is not confirmed in the present study which found no significant differences in boys' and girls' use of mitigation. The girls as well as the boys often used an assertive, unmitigated style in their play. This result is discussed in relation to different patterns of socialization in Langsa, emphasizing the importance of socio-cultural context and peer group influence on children's language, as well as children's sensitivity of contextual norms in their pragmatic competence.
\end{abstract}

Keywords-Politeness, Children's Language, Pragmatic Competence

\section{INTRODUCTION}

What is politeness? Politeness is the feature of language use that most clearly reveals the nature of human sociality as expressed in speech. Politeness is essentially a matter of taking into account the feelings of others as to how they should be interactionally treated, including behaving in a manner that demonstrates appropriate concern for interactors' social status and their social relationship. And then, Are women more polite than men? This is a simple question but actually the answer is extremely complex. Holmes points out that it depends on how we define politeness and and whether or not we accept that the same norms of polite behaviour apply to men and women.in fact, women's use of language appears to be more explicitly polite than men's use of language ${ }^{[1]}$. For example, women are likely to pay more compliments Holmes and Herbert ${ }^{[2]}$ and also they likely to apologize more and do this openly and explicitly (Holmes ${ }^{[1]}$; they are less likely to interrupt their interlocutor, and consequently, they will show up more respect for his/her right to take the floor, and keep it (Zimmerman and West ${ }^{[3]}$; Woods) ${ }^{[4]}$; they often appear more supportive in conversation, for example by providing more positive minimal responses and thus keep the conversation going (Fishman ${ }^{[5]}$; Preisler) ${ }^{[6]}$; and in conversations in general, they seems to be more concerned with their interlocutor's face and then try to avoid face-threatening acts. When we see little boys and girls start to act like men and women, we can see how are gender differences incorporated into the language of them both. Before that, When it comes to children's acquisition of politeness routines, Gleason and Perlman argue that the violations of the sociolinguistic conventions that have to do with politeness are likely to be judged most severely and therefore, unlike the acquisition ${ }^{[7]}$. For example, syntax and semantics, and parents will not leave it to their children to construct their own rules.

\section{THEORETICAL BACKGROUND}

\section{A. Politeness Theory}

Politeness is a concept designating 'proper' social conduct, rules for speech and behavior stemming generally from highstatus individuals or groups. In literate societies such as rules are often formulated in etiquette books. These culture specific notions range from polite formula like please and thank you, the forms of greetings (How are you?) and farewells (Goodbye), etc., to more elaborate routines for table manners, or the protocol for formal events. Politeness is conventionally attached to certain linguistic forms and formulaic expressions, which may be very different in different languages and cultures. This is how the 'person on the street' tends to think about politeness, as inhering in particular forms of words. Yu stated that Politeness seems to be a dominant concept in human interaction ${ }^{[8]}$. Then Robin Lakoff ${ }^{[9]}$. She defines politeness as the verbal realization of proper social behavior which is developed by societies to facilitate interaction among people in society.

In addition, Brown and Levinson define politeness as the attempt to establish, maintain, and face save during a conversation $^{[10]}$. They are used to make the hearer feel good about himself, his interests or possessions, and are commonly used in situations where the audience knows each other fairly well. Politeness in an interaction, can be defined as the means employed to show awareness of another person's face. In this sense, Politeness can be accomplished in situations of social distance or closeness.

They define it as something that is emotionally invested, and it can be lost, maintained or enhanced, and should be constantly attended to in doing interaction in conversation. In 
their opinion, politeness is the use of some strategies through which humans understand and cooperate with each other. Besides, Holmes offers a more recent definition of politeness: "Politeness involves taking account of the feeling of others ${ }^{[1]}$. A polite person should makes others feel comfortable. Being linguistically polite involves speaking to people appropriately in the light of their relationship to you". Furthermore, according to Holmes politeness is an effort to emphasize shared attitudes and values and avoid intruding on other people $^{[1]}$.

\section{B. Children's Language}

Learning to talk is one of the most visible and important achievements of early childhood. New language tools mean new opportunities for social understanding, for learning about the world, for sharing experience, pleasures and needs. Then, in the first three years of school, children take another big step in language development as they learn to read. Although these two domains are distinct, they are also related. Early language skills have been linked to later successful reading. As well, pre-literacy and literacy activities can help further children's language competencies in both the preschool years and later schooling. When children have difficulty understanding others and expressing themselves, it is not surprising that psychosocial and emotional adjustment problems ensue. Children with delayed or disordered language are therefore at increased risk for social, emotional and behavioural problems. Young children's language skills are important to their interpersonal and academic success. It is therefore crucial to have descriptions of normative development that allow identification of children with language impairment and to have an understanding of the mechanisms of language acquisition that can provide a basis for optimizing all children's development (Erika Hoff) ${ }^{[11]}$.

\section{Pragmatic Competence}

Pragmatic Competence is the ability to communicate your intended message with all its nuances in any socio-cultural context and to interpret the message of your interlocutor as it was intended. As critical as this ability is for communication success, it is often not given the emphasis it deserves in the teaching of a second language, with the result that secondlanguage speakers, who lack pragmatic competence, may produce grammatically flawless speech that nonetheless fails to achieve its communicative aims. One area in which the lack of pragmatic competence can create serious problems for a secondlanguage speaker is that of Hedging, a rhetorical strategy that attenuates either the full semantic value of a particular expression, as in He's sort of nice, or the full force of a speech act, as in I must ask you to stop doing that. When non-native speakers fail to hedge appropriately, they may be perceived as impolite, offensive, arrogant, or simply inappropriate. Failing to recognize a hedged utterance, they may misunderstand a native speaker's meaning. This is especially unfortunate when speakers are otherwise fluent, since people typically expect that someone who speaks their language well on the grammatical level has also mastered the pragmatic niceties.

\section{PRESENT STUDY}

This paper is concerned with children's speech when they play. And the results from the present study, most of which has found that girls appear to be more polite than boys when they play. This is not confirmed in the present study which found no significant differences in boys' and girls' use of mitigation. And also investigates the socio-cultural context and peer group influence on children's language, as well as children's sensitivity of contextual norms in their pragmatic competence.

\section{METHOD - PARTICIPANTS, INSTRUMENT}

To find plausible answers to the research questions, researcher used qualitative method and was designed in which a number of requests were collected from a sample of children at Kindergarten in Langsa. As for the method of data collection, survey and observation was used in order to get the data of children speech and language when they are playing at Kindergarten. The children used as participants in this study were five boys and five girls. The children came from middleclass families and were aged between 5 years old and 8 years old.

\section{RESEARCH RESULTS}

\section{A. Survey Results}

The surveys focuses mainly on revealing how well the boys and girls apply politeness $\mathrm{s}$ in their language when they are palying. The data show that $65 \%$ the girls strongly consider themselves polite when they are playing, talking than boys that have $35 \%$. In addition, when they are in same ages, the girls still more polite than boys. So, is definitely sure that the girls show that $60 \%$ in demonstrate pragmatic competence like often use the politeness markers 'please do not feel bad on me, just sit after me ' and 'thank you for give me a candy' while communicating than boys that show about $40 \%$. These survey results reveal that the girls in Kindergarten in Langsa possess the sense of certain rules in terms of politeness, however from playing activity experience it can be said that while communicating in their school, the children rarely use the proper utterances. As a matter of fact, it was necessary to observe the activity process more in a classroom to document the situation vividly. 


\section{B. Observation Results}

The first striking and also easily that noticeable peculiarity of observation was the fact that the palying activity was largely dominated by the girls in using pragmatic while they play. Most of the speech used at the activity were fulled with politness and pragmatic by the children. The children mainly responded to their friends with a good behaviour. The children seem trying hard to make the activity process as pleasant as possible often used positive language.

For example the girl said that 'You are a good boy, Faisal! So, do not disturb your friend when they are playing kites'.

Such a positive attitude obviously encouraged the children and increased their language to be more polite, which reflected positively on their language development. The girls have no eye contact at any point but keep their eyes on the toys. Next, the boys often shouting in accompanied by banging a toy on the table, followed by the aggressive interruption when they are talking the boys, eventually leading to a disruption of the play. These examples are by no means unique; several other examples of girls arguing and using an adversarial style which, in many cases, eventually leads to a disruption of the play, could be included. Finally, if we look to the responses of questions such as "Would you like ..." or "Do you want..." (some coffee/more bricks/another pillow/to borrow my truck, etc.), we get another indicator of polite behaviour. In Langsa, as in most other languages, a polite response, which most parents and also caretakers would like their children to reproduce, to a question like this would be "Yes please" or "No thank you'. In the play scenes, there were 10 examples of these Would-you-like or Do-you-want-questions, and only in one of these cases did the interlocutor respond with a "Yes please". In the other examples, the response was just "Yes" or "No".

\section{Discussions}

It might be tempting to interpret the data presented in this research as evidence that children in Langsa are polite. It is looks like the data reported here tell us something about children's pragmatic competence, and about the importance of seriously considering the context of the play situation. Sachs state that the gender differences in the use of mitigation which she found in her study actually might have three different, but not mutually an exclusive sources ${ }^{[12]}$. The first possible source is that the children learn gender appropriate behaviour by observing first how adults talk to each other, and then to their children. This explanation would be supported by research done by Gleason and her colleagues (for example Gleason ${ }^{[8]}$; Gleason and Perlman ${ }^{[8]}$; Ely et al., $)^{[13]}$, who argue that children's linguistic behaviour may be because of accounted for if we look at the verbal behaviour of their caregivers, most notably their parents.
The second possibility source is that the boys and girls have been treated differently by their parents. This means, that using an assertive, unmitigated (even aggressive) style is acceptable maybe even encouraged for boys, not for girls. Most of people would probably agree the notion of 'a nice girl' and 'a real boy' is more than just a theoretical construct and also has something to do with different constructions of identity in boys and girls something which is encouraged by parents treating boys and girls differently, and by having different expectations of them. Furthemore, To assess the feasibility of this 'Different treatment' hypothesis, here Sachs refers to research by ErvinTripp et al., who explored which consequences various types of speech would have for boys and girls in a family ${ }^{[14]}$. They look at children's compliance gaining with their parents and found that generally. In fact, children of both sexes were more successful when they used a more direct, assertive style when they talk, as opposed to a more indirect, polite style. So, based on these results, the researcher argue that children are usually not being polite in order to get their way but because politeness is an important part of the linguistic systems they are being exposed to.

The third possible explanation source is that the differences of boys' and girls' verbally behaviour may be simply reflect other, more fundamental differences between the sexes. For example, some studies report that boys are more physically active than girls and are more likely to engage in 'rough and tumble. And playing rough in bigger groups outside, we could argue, is more likely to encourage a verbally aggressive style in the boys but not in girls, as opposed to playing in smaller groups inside, which may be more likely to lead to a linguistically more tentative style in the girls.

Lastly, parents' influence on children's speech, this theory may also have some relevance to our data. As mentioned in the introduction, patterns of early child socialisation are somewhat different in Langsa compared to many other village. The vast majority of children are placed in full-time day care at a very early age. In fact, usually when the child is around 6 8 months old. Langsa has changed in terms of early child socialisation. In Langsa, only half of the mothers of young children worked outside of the home and today 9 out of 10 are working mothers. Furthermore, proportionally Langsa almost has the largest number of working parents. This means, for example, that more than $70 \%$ of children in Langsa under the age of 1 year, and almost $90 \%$ of children under 4 , spend about 40 hour more per week in daycare away from their homes.

\section{CONCLUSION}

To sum up explaination above, this paper deals with the use of politeness, peer group influence and pragmatic competence in children language at Kindergartenin Langsa. The majority of previous studies, most of which have focused on middle-class children, has reported important differences 
between boys and girls in terms of their use of politeness phenomena in their play. But these differences were not confirmed yet in the present study, which focused on the use of mitigated and unmitigated forms of language in Langsa preschool children's play in kindergartens and pre-school classes. And children have a high degree of pragmatic competence because almost of them know the contextual norms of the public context which is peer group influence is the predominant force of children's play and also interaction and where assertive behaviour, not politeness, is being rewarded. We can also speculate that they are aware of a different set of norms that applying to the home context where, presumably, parents will expect the children to act and behave politely, and consequently reward them when they do that things.

There is no doubt that in the context of the kindergarten and the pre-school class, Children usually socialise with each other, for example in establishing and maintaining their gender identity, and in the acquisition of sociolinguistic competence, like standard and non-standard language and behaviour for girls and boys respectively. However, this area needs to be much more throughly researched more. Furthermore, this study has emphasised the need to compare the same group of children in the privatly context of the family during dinner table conversations, for example, and the public context of the kindergarten during play with their peers. It would allow us to study of what extent young children are contextually sensitive and can distinguish between pragmatic competence in the private and the public sphere.

\section{References}

[1] Holmes, Janet, 1995. Women, Men and Politeness. Longman, London.
[2] Herbert, Robert K., 1990. Sex-based differences in compliment behaviour. Language in Society 19, 201-224.

[3] West, Candace, Zimmerman, Don, 1983. Small insults: a study of interruptions in cross-sex conversations between unacquainted persons. In: Thorne, Barrie, Kramarae, Cheris, Henley, Nancy (Eds.), Language, Gender and Society. Newbury House, Rowley, MA, pp. 102-117.

[4] Woods, Nicola, 1989. Talking shop: sex and status determinants of floor apportionment in a work setting. In: Jennifer, Coates, Deborah, Cameron (Eds.), Women in Their Speech Communities. Longman, London, pp. 141-157.

[5] Fishman, Pamela, 1983. Interaction: the work women do. In: Thorne, Barrie, Kramarae, Cheris, Henley, Nancy (Eds.), Language, Gender and Society. Newbury House, Rowley, MA, pp. 102-117.

[6] Preisler, Bent, 1986. Linguistic Sex Roles in Conversation. Mouton, Berlin.

[7] Gleason, Jean Berko, Perlman, Rivka V., 1985. Acquiring social variation in speech. In: Giles, Howard, Clair, Robert N. St. (Eds.), Recent Advances in Language, Communication, and Social Psychology. Erlbaum, London.

[8] Yu, M.C. (2003). On the universality of face: evidence from Chinese compliment response behavior. Journal of Pragmatics, 35, 1679-1710.

[9] Lakoff, R. (1973). The logic of politeness: or, minding your p' s and q' s. Papers from The 9th regional meeting. Chicago linguistic society, 292-305.

[10] Brown, P., \& Levinson, S. (1987). Politeness: Some universals in language use. Cambridge: Cambridge University Press.

[11] Hoff, Erika (2009). Language Development at an Early Age: Learning Mechanisms and Outcomes from Birth to Five Years, Department of Psychology, Florida Atlantic University, USA

[12] Sachs, Jacqueline, 1987. Pre-school boys' and girls' language use in pretend play. In: Philips, Susan U., Steele, Susan, Tanz, Christine (Eds.), Language, Gender and Sex in Comparative Perspective. Cambridge University Press, Cambridge, pp. 178-188.

[13] Ely, Richard, Gleason, Jean Berko, McCabe, Alyssa, 1996. "'Why didn't you talk to your mommy, honey?' Parents' and children's talk about talk. Research on Language and Social Interaction 29 (1), 7-25.

[14] Ervin-Tripp, Susan, 1982. Ask and it shall be given you: children's requests. In: Byrnes, H. (Ed.), Georgetown Roundtable on Language and Linguistics. Georgetown University, Washington, DC, pp. 235-245. 